\title{
ARTICLES
}

\section{Egalitarianism in young children}

\author{
Ernst Fehr ${ }^{1,2}$, Helen Bernhard ${ }^{1} \&$ Bettina Rockenbach ${ }^{3}$
}

\begin{abstract}
Human social interaction is strongly shaped by other-regarding preferences, that is, a concern for the welfare of others. These preferences are important for a unique aspect of human sociality-large scale cooperation with genetic strangersbut little is known about their developmental roots. Here we show that young children's other-regarding preferences assume a particular form, inequality aversion that develops strongly between the ages of 3 and 8 . At age 3-4, the overwhelming majority of children behave selfishly, whereas most children at age 7-8 prefer resource allocations that remove advantageous or disadvantageous inequality. Moreover, inequality aversion is strongly shaped by parochialism, a preference for favouring the members of one's own social group. These results indicate that human egalitarianism and parochialism have deep developmental roots, and the simultaneous emergence of altruistic sharing and parochialism during childhood is intriguing in view of recent evolutionary theories which predict that the same evolutionary process jointly drives both human altruism and parochialism.
\end{abstract}

Other-regarding preferences are decisive for the human ability to achieve and maintain cooperation in large groups of genetic strangers $^{1,2}$. If an individual cares for the welfare of other group members, he or she is more likely to refrain from free-riding in cooperative projects. Similarly, if an individual dislikes the free-riding of othersbecause it is associated with inequality ${ }^{3-5}$ or because it represents a norm violation ${ }^{6}$ - the individual is more likely to punish freeriders $^{7-9}$. This punishment then constitutes an incentive for potential free-riders to cooperate. Other-regarding preferences are also important in public life and politics ${ }^{10}$ and they powerfully amplify reputational incentives in strategic interactions, thus contributing to the cooperation-enhancing force of reputation opportunities ${ }^{11-14}$.

The developmental origins and proximate mechanisms behind other-regarding preferences are not well understood, however, despite recent progress ${ }^{15-22}$. Because we know little about when young children start to take the welfare of others into account, we conducted experiments with 229 young, genetically unrelated, Swiss children ( 127 girls and 102 boys) between the ages of 3 and 8 . An understanding of the development of other-regarding preferences in children may enable us to gain deeper insights into the proximate and ultimate sources of species differences in preferences and cooperation. The study of children's preferences is also of particular interest in light of recent experiments in non-human primates ${ }^{23-27}$, allowing a more direct comparison between human and non-human primates. Experiments with non-human primates have, for example, demonstrated that chimpanzees show little willingness to provide food to a familiar conspecific in situations where they could do so with no or only a small $\operatorname{cost}^{23,24,27}$. In view of this result, it is interesting to study whether (and if so, when) children are willing to provide valuable resources to their partners. In this way, the large species differences in cooperation between humans and non-human primates can be more directly traced back to species differences in other-regarding preferences.

Investigation of the development of moral judgment ${ }^{28}$ and prosocial behaviour $^{29-35}$ is a rich tradition in psychology, but there is a surprising lack of studies that isolate the development of otherregarding preferences from the development of other forms of prosocial behaviour. The experimental study of other-regarding preferences in humans involves the conduct of one-shot experiments with anonymous interaction partners because the behaviour in nonanonymous face-to-face interactions, or in repeated interactions with the same partner, can easily be affected by selfish motives. A subject could, for example, behave prosocially because of the expectation of future benefits from the partner that accrue as a result of prosocial behaviour in the current interaction. Selfish motives could therefore drive prosocial behaviours such as sharing a valuable resource in non-anonymous face-to-face interactions or in repeated interactions between the experimental subjects. Measuring otherregarding preferences without such confounds thus requires the conduct of anonymous one-shot experiments.

\section{Testing for inequality aversion in children}

For this reason, we conducted experiments with young children that enabled us to measure other-regarding preferences such as inequality aversion. In the context of our experiments, inequality aversion prevails if subjects prefer allocations that reduce the inequality between themselves and their partner, regardless of whether the inequality is to their advantage or disadvantage ${ }^{3}$.

Each subject participated in the three treatments described below and was paired with one other anonymous partner in each treatment. Each treatment condition was explained in detail to the decision maker so that we could be sure that the child had completely understood the experiment and the consequences of the different choices (see Methods and Supplementary Methods). In all treatments, the decision maker allocated units of sweets (smarties, jellybabies or fizzers) to himself and/or to the partner. In the 'prosocial' treatment, which was inspired by recent experiments with chimpanzees ${ }^{23,24}$, the subject could choose between the allocation $(1,1)$-that is, 1 for himself, 1 for partner-and the allocation $(1,0)$. This treatment measures some elementary form of prosociality, because by choosing $(1,1)$ the subject can at no cost to himself deliver a benefit to the partner and, thus, avoid advantageous inequality. In principle, the choice of $(1,1)$ can be driven by the equality motive ${ }^{3}$ or by a motive to increase the partner's payoff or both parties joint payoff ${ }^{36}$. Economic self-interest is not involved in the prosocial game because the decision maker receives one unit regardless of which choice he makes. It is therefore also possible that a selfish individual who does not care about the partner's payoff will choose $(1,1)$. In fact, because there is 
no reason for a selfish individual to make either choice, a population of self-interested individuals would choose $(1,1)$ in $50 \%$ of the cases. For this reason, evidence for other-regarding behaviour in the prosocial game requires that the population of children choose $(1,1)$ significantly above $50 \%$ frequency.

In the 'envy' treatment, the subject could choose between $(1,1)$ and $(1,2)$. Here again, it is possible to deliver a benefit to the partner at no cost, but the choice $(1,2)$ leads to disadvantageous inequality for the decision maker. Thus, if an individual just wants to increase the partner's or the joint payoff, he should choose $(1,1)$ in the prosocial treatment and $(1,2)$ in the envy treatment. In contrast, if the equality motive drives behaviour in these two conditions, the subject chooses $(1,1)$ in both treatments, thus avoiding the unequal allocations $(1,0)$ in the prosocial treatment and $(1,2)$ in the envy treatment. However, as in the prosocial treatment, a purely selfish individual has no reason to make either choice in the envy treatment. For this reason, evidence for the equality motive in the envy game again requires that the population of children choose $(1,1)$ significantly above $50 \%$ frequency.

In a third condition, the 'sharing' treatment, the subject could choose between $(1,1)$ and $(2,0)$. This treatment measures a strong form of inequality aversion because the provision of a benefit for the partner is costly for the subject. Selfish children should therefore never make the egalitarian choice in this treatment, indicating that the choice of $(1,1)$ unambiguously suggests an other-regarding preference. The sharing treatment also enables us to measure altruism as defined by evolutionary biology because sharing implies a costly transfer of a valued resource to another individual.

In addition to these treatments, we also implemented an ingroup and an outgroup condition 'across subjects'. In the ingroup condition, the partner came from the same playschool, kindergarten or school, whereas the partner came from another playschool, kindergarten or school in the outgroup condition. The rationale for the outgroup condition is provided by evidence and theory indicating that parochialism strongly shapes adult human altruism ${ }^{37-39}$, and that the same evolutionary process might determine the development of both human altruism and parochialism ${ }^{40}$.

\section{From self-interest to inequality aversion}

Among the 3-4-yr-old children, most behaved selfishly in the ingroup condition of the sharing game because only $8.7 \%$ of the children were willing to share (Fig. 1). The fact that the frequency of $(1,1)$ choices did not differ significantly from $50 \%$ in the prosocial game and in the envy game further supports the low incidence of other-regarding preferences at this age (binomial test; $P=0.21$ for the prosocial game, $P=0.68$ for the envy game; $n=23)$. The prevalence of selfish behaviour in the sharing game decreased slightly for 5-6-yr-old children, but 78\% were still not willing to share at this age. Also, as with the 3-4-yr-old children, the frequency of egalitarian choices in the prosocial and the envy game for the 5-6-yr-olds was not significantly different from $50 \%$ (binomial test; $P=0.24$ for the prosocial game, $P=0.41$ for the envy game; $n=36$ ). A substantially different picture emerged, however, for children at ages 7-8 (Fig. 1): $45 \%$ of them showed sharing behaviour, and we also found strong evidence for other-regarding preferences in the other two games. Of the 7-8-yr-olds, $78 \%$ preferred the egalitarian allocation in the prosocial game, refuting the null hypothesis of random choices (binomial test, $P<0.001, n=56$ ). Similarly, an overwhelming majority $(80 \%)$ preferred the egalitarian alternative in the envy game at this age (binomial test, $P<0.001, n=56$ ).

Taken together, the behavioural patterns across all three games suggest that children at age 3-4 show little willingness to share resources but a non-negligible percentage of the children is willing to make choices that benefit the recipient if it is not costly. After this age, other-regarding preferences develop, which take the form of inequality aversion instead of a simple preference for increasing the partner's or the joint payoff. If the motive to increase the partner's or the joint payoff were to drive the children's other-regarding prefer- ences, they would have then chosen the alternative $(1,2)$ in the envy game. In fact, however, most of the children at age 7-8 preferred the egalitarian allocation.

Therefore, if we pool the children's choices across the various games, we find that both strongly and weakly egalitarian choices show a large increase with age (Fig. 2, Supplementary Fig. 3 and Supplementary Table 1). Egalitarianism, which is characterized by a $(1,1)$ choice both in the prosocial and the envy game (red columns in Fig. 2), increases from $21 \%$ at age $3-4$ to $33 \%$ at age 5-6, whereas $60 \%$ prefer the egalitarian allocation in both games at age $7-8$. The percentage of egalitarian choices at age 7-8 significantly differs from an independent random choice in each of both games (binomial test, $P<0.0001, n=56)$. If the children had made independent, random choices, only $25 \%$ of them would have chosen $(1,1)$ in both the prosocial and the envy game. If we pool the children's choices in all three games, the percentage of children who preferred the egalitarian allocation in all three games increases from $4 \%$ at age 3-4 to $30 \%$ at age $7-8$ (Fig. 2). Thus, among those children who choose the egalitarian allocation in the prosocial and the envy game at age $7-8$, roughly $50 \%$ share resources in the sharing game. The other $50 \%$ choose the selfish allocation $(2,0)$ in the sharing game.

It is notable that the share of subjects who maximize the partner's payoff by choosing both $(1,1)$ in the prosocial game and $(1,2)$ in the envy game (blue columns in Fig. 2) decreases sharply from $43 \%$ at age $3-4$ to $16 \%$ at age $7-8$. Furthermore, the percentage of subjects who maximize the partner's payoff in all three games is only roughly $5 \%$ and does not change much with age. The across-game perspective also enables us to identify a third type of subject whom we call 'spiteful' because they minimize the partner's payoff in all three games. The share of spiteful subjects is $22 \%$ at age 3-4 and 5-6 and decreases slightly to $14 \%$ at age $7-8$, a percentage that is similar to the relative share of spiteful subjects observed in adult subject pools ${ }^{41,42}$.

\section{Parochial egalitarianism}

Parochial tendencies affected children's choices in all three treatments, and these tendencies are pervasive in the sharing and prosocial

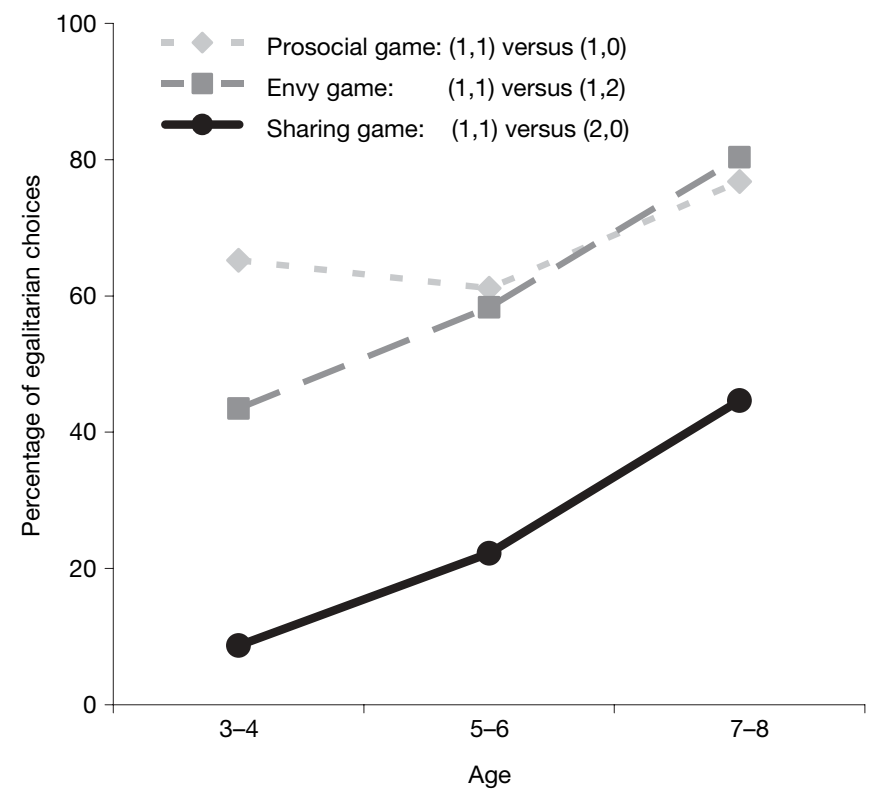

Figure 1 | The relative frequency of egalitarian choices across all ingroup treatments. In these treatments, the decision maker's choice determines the resources of an ingroup partner. The frequency of egalitarian choices strongly increases with age across all three ingroup treatments, and most children prefer equality at age 7-8 in the prosocial and the envy game. However, if equality is costly for the children, they choose the egalitarian allocation less frequently-as indicated by the behaviour in the sharing game- and at age 3-4, self-interested choices dominate almost completely. 
games (Fig. 3). The egalitarian choice is roughly 15\%-20\% more likely in the prosocial game if the partner is an ingroup member (Fig. 3a). This difference is highly significant (ingroup dummy in probit regression, $P=0.004, z=2.92, n=229$ ) and a similar ingroup-outgroup gap prevails across all ages. The largest difference was found in the sharing game (Fig. 3b), where we observed a strong increase in the frequency of egalitarian choices if the partner was from the ingroup (age effect in probit regression, $P=0.001, z=3.33$, $n=115$ ), whereas the children's willingness to share even slightly declined with age in the outgroup condition although this was not significant (age effect in probit regression, $P=0.123, z=-1.54$, $n=114)$. We did observe, however, a highly significant interaction effect between age and outgroup condition (probit regression, $P<0.001, z=3.50, n=229)$, indicating that the difference between sharing in the ingroup and outgroup conditions strongly increases with age. Thus, the children's altruism and parochialism emerges simultaneously between the ages of 3 and 8 and is associated with a very strong ingroup bias at age $7-8$ (probit regression, $P<0.001$, $z=3.58, b=105$ ), with very little willingness to share with an outgroup member (only 12\% of the children shared in the outgroup condition at this age).

The prevalence of egalitarian choices in the envy game developed earlier in the outgroup condition, where the children at age 5-6 already overwhelmingly favour the $(1,1)$ allocation (Fig. 3c). The willingness to remove disadvantageous inequality towards ingroup members becomes so prevalent at age 7-8 that an ingroup-outgroup gap no longer exists. However, averaging across gender hides an important gender effect in the envy game: boys show much stronger parochial tendencies than girls do because boys seem to be much less averse against disadvantageous inequality if the partner is an ingroup member (Fig. 4a; outgroup dummy in probit regression controlling

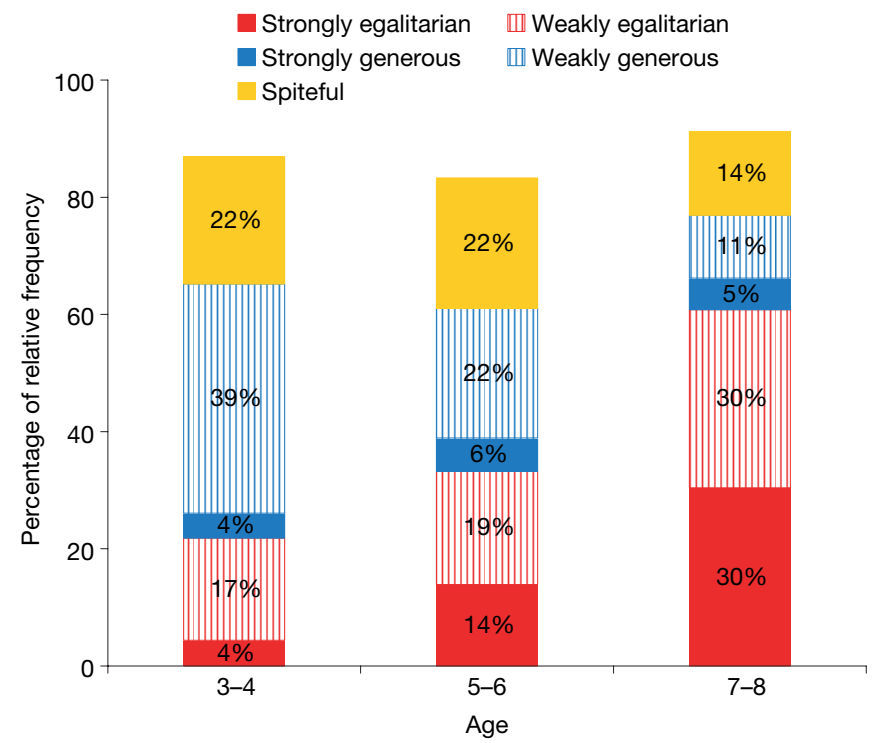

Figure 2 Behavioural types in the ingroup condition. The figure classifies subjects according to their behaviour in all three games, that is, in the prosocial game $((1,1)$ versus $(1,0))$, the sharing game $((1,1)$ versus $(2,0))$, and the envy game $((1,1)$ versus $(1,2))$. Strongly egalitarian subjects choose the egalitarian allocation in all three games. Weakly egalitarian subjects choose the egalitarian allocation only in the prosocial and the envy games, but not in the sharing game, where egalitarian behaviour is costly. Strongly generous subjects choose the allocation that maximizes the partner's payoff in all three games. Weakly generous subjects maximize the partner's payoff only in the prosocial and the envy games, but not in the sharing game, where generous behaviour is costly. Spiteful subjects choose the allocation that minimizes the partner's payoff in all three games. The percentage of egalitarian subjects increases steeply with age, whereas the share of generous subjects declines. Moreover, most subjects who are willing to share at age 7-8 belong to the egalitarian and not to the generous type of subjects. for age, $P=0.001, z=3.23, n=102$ ). In contrast, girls do not differentiate in their choices between ingroup and outgroup partners (Fig. 4b; outgroup dummy in probit regression controlling for age, $P=0.663, z=-0.44, n=127$ ), but, like boys, they also show an increasing trend towards egalitarian choices in the envy game as they become older.

\section{Birth order and sibling effects}

We find a strong 'only child' and 'youngest child' effect in the sharing game. Children without siblings showed much more costly sharing behaviour than children with siblings. On average, children without siblings were $28 \%$ more likely to share than children with siblings-a highly significant difference (probit regression, $P=0.006, z=2.75$, $n=197$ ) that also exists if we control for income effects (see Supplementary Data). With increasing age, however, the difference between children with and without siblings decreases slightly, as indicated by an interaction effect between 'child without siblings' and 'age' in a probit regression $(P=0.022, z=-2.29, n=197)$. Among the children with siblings, we found that-regardless of age- the youngest children in a family were $17 \%$ less willing to share than children with younger siblings (probit regression controlling for age, $P=0.007, z=2.71, n=172$ ). Thus, it seems that the mere existence of siblings or birth order may have an important role in determining altruistic behaviours. Further analyses and interpretation of the effects of birth order and other demographic and psychological characteristics can be found in the Supplementary Information.

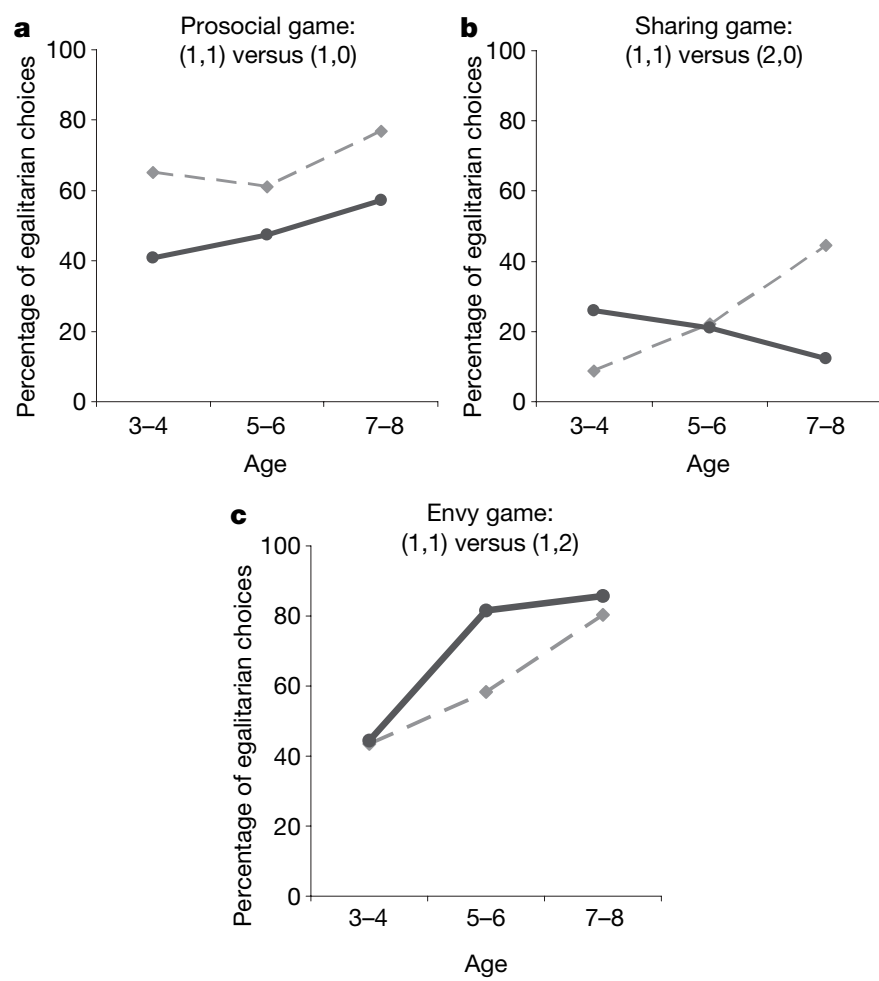

Figure 3 Egalitarian choices across ingroup and outgroup conditions. Grey dashed lines denote when the partner was an ingroup member; black solid lines represent when the partner was an outgroup member $(\mathbf{a}-\mathbf{c})$. $\mathbf{a}$, In the prosocial game, the children remove inequality that favours themselves more often if the partner is an ingroup member. $\mathbf{b}$, Egalitarian choices slightly decrease over time in the sharing game (with very little sharing at age 7-8) if the partner is an outgroup member, whereas sharing with ingroup members strongly increases with age, providing strong evidence for parochial altruism in children. c, In the envy game, children develop a preference for equality much earlier if the partner is an outgroup member but eventually the aversion against disadvantageous inequality with regard to ingroup members becomes so strong that ingroup-outgroup differences are small. 


\section{Discussion}

The development of inequality aversion relatively early in childhood is particularly interesting in the light of ethnographic evidence that suggests that there is a strong role of egalitarian 'instincts' in human evolutionary history. There is considerable ethnographic evidence that egalitarian concerns have shaped many human small-scale societies $^{43,44}$. For example, sharing of large hunted game across families seems to have been the rule rather than the exception in small-scale societies, and egalitarian sentiments also play a part in contemporary large-scale societies ${ }^{4,5}$. The important role of egalitarian sentiments in human evolutionary history raises the possibility that there may have been cultural or even genetic transmission that favours egalitarian behaviours. In fact, recent evidence from behavioural genetics suggests that egalitarian behaviour in the ultimatum game has a genetic component ${ }^{45}$.

The simultaneous development of altruistic behaviour and parochialism and the gender differences in parochialism are also interesting in view of evolutionary theories that predict that the same evolutionary process ${ }^{40}$ jointly determines human altruism and parochialism, meaning that these traits co-evolve in such a way that either both or neither of them evolves. According to the theory, the driving force behind this evolutionary process is frequent intergroup conflict. Because mainly males were involved in intergroup fights, it seems possible that evolution favoured a gender bias in parochialism.
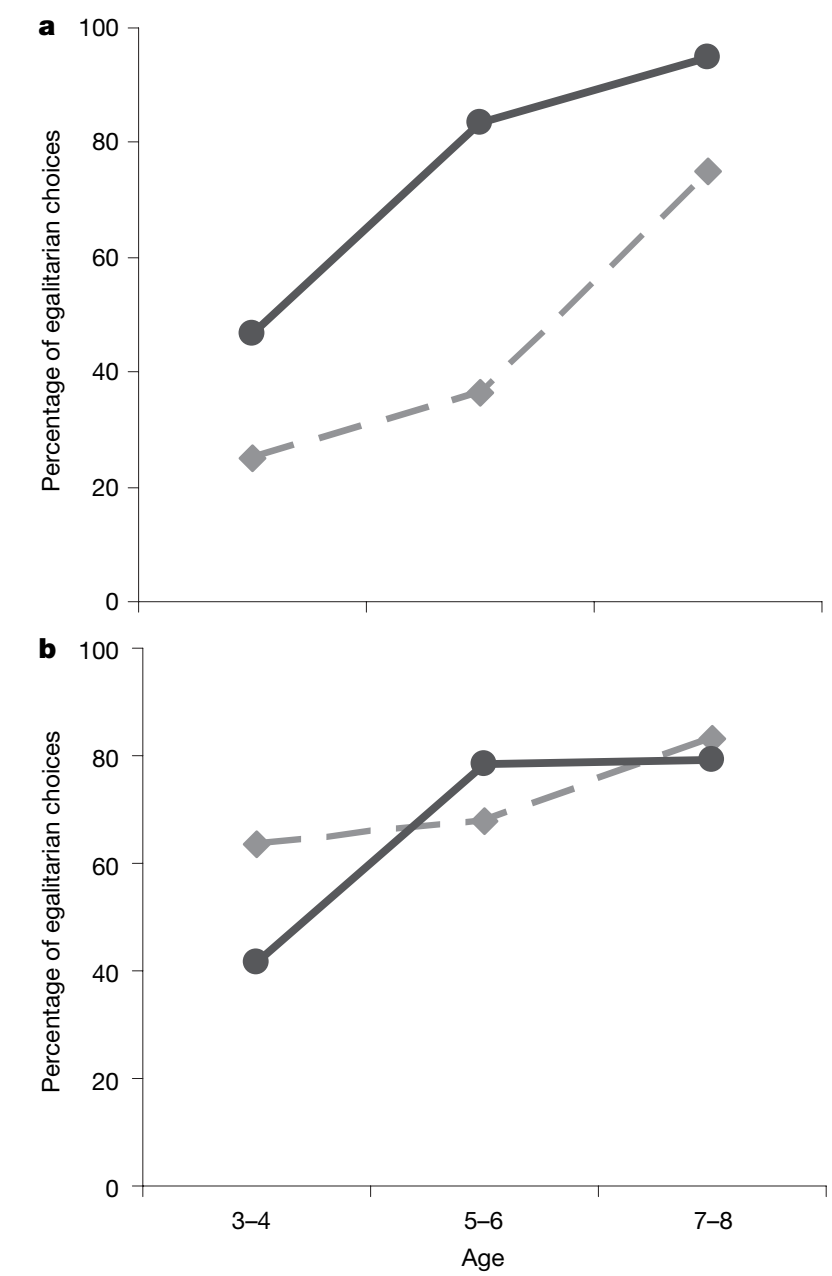

Figure 4 | Gender differences in parochial egalitarianism in the envy game where the child could choose between $(1,1)$ and $(1,2)$. a, b, The propensity of boys (a) and girls (b) for egalitarian choices in the ingroup (grey dashed line) and outgroup (black solid line) condition. The difference between ingroup and outgroup condition is large for boys but virtually absent for girls.
In fact, a payoff advantage relative to the outgroup may have been particularly advantageous for males because it strengthened the ingroup's position in intergroup conflicts. Males bore the main cost of intergroup conflict in terms of injuries and deaths and often gained more than females in the case of victory because of the increase in the pool of potential mating partners ${ }^{46}$. Thus, evolution may have favoured a greater sensitivity in males for payoff advantages relative to outgroup members. In view of this prediction, we find it notable that boys showed a much stronger ingroup bias than girls in the envy game.

These potential evolutionary roots of human egalitarianism and parochialism do not preclude culture and socialization from playing an important part in other-regarding preferences; they may even be a main factor in their evolution ${ }^{2,47}$. As the children move from an informal playgroup to kindergarten and then on to formal schools, they may learn that equality is a rule that the authorities (for example, the teachers) endorse. Thus, the children probably acquire some of the normative rules of the society which surrounds them during the age period on which we focused ${ }^{30}$. In this context, it is interesting that the motive to increase the partner's payoff declined strongly between ages 3 and 8 , whereas egalitarian behaviour strongly increased in this age period (Fig. 2), providing a hint about the content of the normative rule they acquired. The children may also become more sensitive with regard to the opinions of others about themselves, a cognition which requires the ability to understand that one's actions affect what other people believe about oneself. Recent evidence indicates that adult humans care even about what anonymous others may think about them ${ }^{48,49}$. Theory-of-mind and perspective-taking abilities are certainly conducive to such social cognitions. Therefore, if older children care about what anonymous others think about them, they may be more prone to behave in a normatively appropriate way because-owing to their age - they are more likely to have theory-ofmind and perspective-taking abilities ${ }^{30,50}$.

Our results also indicate that important inter-species differences occur in other-regarding preferences when compared to the patterns observed in chimpanzees ${ }^{23,24,27}$ and marmosets ${ }^{26}$. In the prosocial game, adult chimpanzees, who could allocate food in a face-to-face interaction to a familiar recipient, did not show a significant preference for the $(1,1)$ choice ${ }^{23,24,27}$, whereas most of the children develop a preference for the egalitarian choice in this game even though their partner is anonymous. Furthermore, as the sharing game indicates, many children at age $7-8$ are also willing to share with an anonymous ingroup member. The facts in the envy game also contrast sharply with experimental findings in both chimpanzees and marmosets. The children developed a widespread aversion against disadvantageous inequality, whereas chimpanzees have been shown to be unwilling to take actions to remove inequality between themselves and a conspecific ${ }^{24}$, and marmosets even tend to take actions that generate disadvantageous inequality for themselves if the action provides food for the partner ${ }^{26}$. In view of the decisive role of otherregarding preferences for a species ability to achieve large-scale cooperation, the observed inter-species differences are probably important in explaining why humans are so exceptionally cooperative.

\section{METHODS SUMMARY}

Each child played all three games against anonymous partners. To avoid satiation effects, three different currencies (smarties, jellybabies and fizzers) were used in randomized order in the three games. In each game, subjects had two mutually exclusive choices that were represented with two cardboards; we drew two circles with arrows on each (see Supplementary Fig. 1). One arrow pointed to the decision maker, illustrating that the sweets in that circle goes to him or her, whereas the other arrow pointed to a group photo which had been made earlier. In the ingroup condition, the group photo showed the members of the child's playgroup, kindergarten or school, whereas it showed the members of a different playgroup, kindergarten or school in the outgroup condition. The photos were used to communicate the partner's ingroup or outgroup status to the children in the game. Depending on whether the ingroup or the outgroup condition applied, the decision maker was told that the sweet(s) in the other circle (if there were any 
in that circle) would be given to one of the children on the ingroup photo or outgroup photo, respectively. If there was no sweet in the circle, it was made clear to the child that the choice of the corresponding cardboard indicates that the partner would receive nothing. We also controlled for the spatial assignment of the different alternative. In the prosocial game, for example (shown in Supplementary Fig. 1), the alternative $(1,1)$ was randomly assigned to the left or right side. Thus, preferences for left or right cannot explain any of our findings. We also made it clear to the children that neither other children nor their parents or teachers will be informed about their decisions (see Supplementary Methods).

Full Methods and any associated references are available in the online version of the paper at www.nature.com/nature.

\section{Received 12 March; accepted 6 June 2008.}

1. Bowles, S. Microeconomics: Behavior, Institutions and Evolution 93-126 (Princeton Univ. Press, 2004).

2. Boyd, R. T. \& Richerson, P. The Origin and Evolution of Cultures (Oxford Univ. Press, 2005).

3. Fehr, E. \& Schmidt, K. M. A theory of fairness, competition, and cooperation. Q. J. Econ. 114, 817-868 (1999)

4. Fowler, J. H., Johnson, T. \& Smirnov, O. Human behaviour: Egalitarian motive and altruistic punishment. Nature 433, E1 (2007).

5. Dawes, C. T. et al. Egalitarian motives in humans. Nature 446, 794-796 (2007).

6. Falk, A. \& Fischbacher, U. A theory of reciprocity. Games Econ. Behav. 54, 293-315 (2006).

7. Fehr, E. \& Gächter, S. Altruistic punishment in humans. Nature $415,137-140$ (2002).

8. Gürerk, O., Irlenbusch, B. \& Rockenbach, B. The competitive advantage of sanctioning institutions. Science 312, 108-111 (2006).

9. Hauert, C. et al. Via freedom to coercion: The emergence of costly punishment. Science 316, 1905-1907 (2007).

10. Fong, C., Bowles, S. \& Gintis, H. in Handbook on the Economics of Giving, Reciprocity, and Altruism (eds Kolm, S.-C. \& Ythier, J. M.) (Elsevier, 2006).

11. Milinski, M., Semmann, D. \& Krambeck, H. J. Reputation helps solve the 'tragedy of the commons'. Nature 415, 424-426 (2002).

12. Brown, M., Falk, A. \& Fehr, E. Relational contracts and the nature of market interactions. Econometrica 72, 747-780 (2004).

13. Nowak, M. A. \& Sigmund, K. Evolution of indirect reciprocity. Nature 437, 1291-1298 (2005)

14. Rockenbach, B. \& Milinski, M. The efficient interaction of indirect reciprocity and costly punishment. Nature 444, 718-723 (2006).

15. Harbaugh, W. T. \& Krause, K. Children's altruism in public good and dictator experiments. Econ. Inq. 38, 95-109 (2000)

16. de Quervain, D. J.-F. et al. The neural basis of altruistic punishment. Science 305, 1254-1258 (2004).

17. Sutter, M. Outcomes versus intentions: On the nature of fair behavior and its development with age. J. Econ. Psychol. 28, 69-78 (2007).

18. Sutter, M. \& Kocher, M. G. Trust and trustworthiness across different age groups. Games Econ. Behav. 59, 364-382 (2007)

19. Benenson, J. F., Pascoe, J. \& Radmore, N. Children's altruistic behavior in the dictator game. Evol. Hum. Behav. 28, 168-175 (2007)

20. Fliessbach, K. et al. Social comparison affects reward-related brain activity in the human ventral striatum. Science 318, 1305-1308 (2007)

21. Cesarini, D. et al. Heritability of cooperative behavior in the trust game. Proc. Nat Acad. Sci. USA 105, 3721-3726 (2008).

22. Ellingsen, T. \& Johannesson, M. Anticipated verbal feedback induces altruistic behavior. Evol. Hum. Behav. 29, 100-105 (2008).

23. Silk, J. B. et al. Chimpanzees are indifferent to the welfare of unrelated group members. Nature 437, 1357-1359 (2005).

24. Jensen, K., Hare, B., Call, J. \& Tomasello, M. What's in it for me? Self-regard precludes altruism and spite in chimpanzees. Proc. Biol. Sci. 273, 1013-1021 (2006).

25. Jensen, K., Call, J. \& Tomasello, M. Chimpanzees are rational maximizers in an ultimatum game. Science 318, 107-109 (2007).

26. Burkart, J. M., Fehr, E., Efferson, C. \& van Schaik, C. P. Other-regarding preferences in a non-human primate: Common marmosets provision food altruistically. Proc. Natl Acad. Sci. USA 104, 19762-19766 (2007).
27. Vonk, J. et al. Chimpanzees do not take advantage of very low cost opportunities to deliver food to unrelated group members. Anim. Behav. 75, 1757-1770 (2008).

28. Turiel, E. in Handbook of Child Psychology Vol. 3 (eds Damon, W. \& Eisenberg, N.) 863-932 (Wiley and Sons, 1998).

29. Knight, G. P. \& Kagan, S. Development of prosocial and competitive behaviors in anglo-american and mexican-american children. Child Dev. 48, 1385-1394 (1977)

30. Eisenberg, N. \& Mussen, P. H. The Roots of Prosocial Behavior in Children (Cambridge Univ. Press, 1989).

31. Thompson, C., Barresi, J. \& Moore, C. The development of future-oriented prudence and altruism in preschoolers. Cogn. Dev. 12, 199-212 (1997).

32. Eisenberg, N. \& Fabes, R. A. in Handbook of Child Psychology Vol. 3 (eds Damon, W. \& Eisenberg, N.) 701-778 (Wiley and Sons, 1998).

33. Murnigham, J. K. Ultimatum bargaining by children and adults. J. Econ. Psychol. 19, 415-445 (1998)

34. Warneken, F. \& Tomasello, M. Altruistic helping in human infants and young chimpanzees. Science 311, 1301-1303 (2006).

35. Warneken, F. et al. Spontaneous altruism by chimpanzees and young children. PLoS Biol. 5, e184 (2007)

36. Charness, G. \& Rabin, M. Understanding social preferences with simple tests. Q. J. Econ. 117, 817-869 (2002)

37. Goette, L., Huffman, D. \& Meier, S. The impact of group membership on cooperation and norm enforcement: Evidence using random assignment to real social groups. Am. Econ. Rev. 96, 212-216 (2006)

38. Bernhard, H., Fischbacher, U. \& Fehr, E. Parochial altruism in humans. Nature 442, 912-915 (2006)

39. Shinada, M., Yamagishi, T. \& Ohmura, Y. False friends are worse than bitter enemies: "Altruistic" punishment of in-group members. Evol. Hum. Behav. 25, 379-393 (2004)

40. Choi, J. K. \& Bowles, S. The coevolution of parochial altruism and war. Science 318, 636-640 (2007).

41. Van Lange, P. A. M. The pursuit of joint outcomes and equality in outcomes: An integrative model of social value orientation. J. Pers. Soc. Psychol. 77, 337-349 (1999).

42. Falk, A., Fehr, E. \& Fischbacher, U. Driving forces behind informal sanctions. Econometrica 73, 2017-2030 (2005)

43. Boehm, C. Egalitarian behavior and reverse dominance hierachy. Curr. Anthropol. 34, 227-254 (1993).

44. Boehm, C. Impact of the human egalitarian syndrome on darwinian selection mechanics. Am. Nat. 150, S100-S121 (1997)

45. Wallace, B., Cesarini, D., Lichtenstein, P. \& Johannesson, M. Heritability of ultimatum game responder behavior. Proc. Natl Acad. Sci. USA 104, 15631-15634 (2007).

46. Chagnon, N. A. Life histories, blood revenge, and warfare in a tribal population. Science 239, 985-992 (1988).

47. Henrich, J. et al. "Economic man" in cross-cultural perspective: behavioral experiments in 15 small-scale societies. Behav. Brain Sci. 28, 795-855 (2005).

48. Dana, J., Cain, D. M. \& Dawes, R. M. What you don't know won't hurt me: Costly (but quiet) exit in dictator games. Organ. Behav. Hum. Decis. Process. 100, 193-201 (2006).

49. Ellingsen, T. \& Johannesson, M. Paying respect. J. Econ. Perspect. 21, 135-149 (2007).

50. Wellman, H. M., Cross, D. \& Watson, J. Meta-analysis of theory-of-mind development: The truth about false belief. Child Dev. 72, 655-684 (2001).

Supplementary Information is linked to the online version of the paper at www.nature.com/nature.

Acknowledgements This paper is part of the Research Priority Program 'Foundations of Human Social Behaviour-Altruism versus Egoism' at the University of Zurich and of the Swiss National Competence Center in research on affective sciences, which is financed by the Swiss National Science Foundation. We also thank N. Kessler for her research assistance during the conduct of the experiments.

Author Information Reprints and permissions information is available at www.nature.com/reprints. Correspondence and requests for materials should be addressed to E.F. (efehr@iew.uzh.ch) or B.R. (bettina.rockenbach@uni-erfurt.de). 


\section{METHODS}

Subjects. We recruited young children (3-8-yr-old) from playschools, kindergartens and first grades for our experiments. We received permission for the experiments from the school president, the school board, the teachers and the parents. Of the parents that we asked, $92 \%$ agreed so that a total of 229 children participated in the study: 62 children from playschools, 75 from kindergartens and 92 children from grade one. The children live in Rapperswil-Jona, a small city in the canton of St Gallen, Switzerland. Two women aged between 20 and 25 conducted the experiment. The experimental instructions are reproduced in the Supplementary Information.

Experimental procedures. Each child played the prosocial game, the envy game and the sharing game against anonymous partners. The order of the games was counterbalanced across subjects. The partners came either from the ingroup (same playschool, kindergarten or school) or from an outgroup (a different playschool, kindergarten or school).

Payoffs. We needed an experimental currency desirable for the younger and older children in our sample. Therefore we decided to use various sweets. To avoid satiation effects, a different currency was used in each of the three games (smarties, jellybabies or fizzers), and these were randomized across games. Before the experiment started, we asked each child whether he or she likes those sweets (all of them did). At the end of all three treatments we asked each child whether they liked all three sweets the same or whether they liked one more than the other. If they indicated that they liked some of the sweets more than the others we asked which they liked the most and least (see Supplementary Information). The average 'liking rates' of the different currencies were identical. Moreover, we asked the parents to rate on a 7-point scale how much their children value the sweets and their answers showed that our currencies provide equally strong incentives for the children across all ages.

The choice situation. To ensure that the children could easily understand the choice problem, we used a set up that made the two available choices transparent. The two mutually exclusive choices were represented with two cardboards; we drew two circles with arrows on each (see Supplementary Fig. 1). One arrow pointed to the decision maker, illustrating that the sweet in that circle goes to him or her, whereas the other arrow pointed to a group photo which had been made earlier. In the ingroup condition, the group photo showed the members of the child's playgroup, kindergarten or school, whereas it showed the members of a different playgroup, kindergarten or school in the outgroup condition. The photos were used to communicate the partner's ingroup or outgroup status to the children in the game. Depending on whether the ingroup or the outgroup condition applied, the decision maker was told that the sweet(s) in the other circle (if there were any in that circle) would be given to one of the children on the ingroup photo or outgroup photo, respectively. If there was no sweet in the circle, it was made clear to the child that the choice of the corresponding cardboard implies that the partner would receive nothing. The advantage of this design is that the same procedure can be used for the ingroup and the outgroup condition, and that the children can grasp the partner's ingroup or outgroup status very easily. In fact, many children across all ages immediately expressed their knowledge of the children on the photo, that is, they spontaneously indicated that they knew or did not know the children in the photo. On the basis of this spontaneous insight, it was then easy to explain that the partner will be a member of the child's group or the member of another group.

We also controlled for the spatial assignment of the different alternatives. In the prosocial game, for example, which is shown in Supplementary Fig. 1 (Supplementary Methods), the alternative $(1,1)$ was randomly assigned to be on the left or the right side. Thus, preferences for left or right cannot explain any of our findings. We also made it clear to the children that neither other children nor their parents/teachers would be informed about their decisions.

Before a child played a game we ensured that he or she fully understood the game situation (that is, the available choices, the implications of different choices for the allocation of currencies for 'self' and 'partner', the partner's ingroupoutgroup status, and so on). The subjects had to answer several questions for this purpose (Supplementary Methods). Only three children had problems in answering these questions, which shows that we successfully implemented the three games even for the youngest participants in the sample. The three children who could not answer correctly were excluded from the data analyses (229 is the number of children who correctly answered the questions). Once the children had answered the questions correctly, they were asked to make a decision in the first game before the second game was presented and explained. Because we ensured that the children understood the payoff implications of the two available choices very well and because it was clear that the choices were mutually exclusive (that is, only one cardboard could be chosen), the children did not make mistakes while choosing, for example, by indicating that they wanted to choose both cardboards. Nor did any children reverse their opinion during the choice process, that is, children who first chose one cardboard but later switched to the other.

Questionnaire. After all children had participated in the experiment we sent the parents a questionnaire in which we asked them about characteristics of their child, such as whether he or she can easily imagine how other children feel ('empathy'), whether there are siblings, the birth order, who primarily cares for the child during the day, the number of regular playmates, and so on. We sent 198 questionnaires to the parents and 161 questionnaires were sent back. The questionnaire is reprinted in the Supplementary Information. 